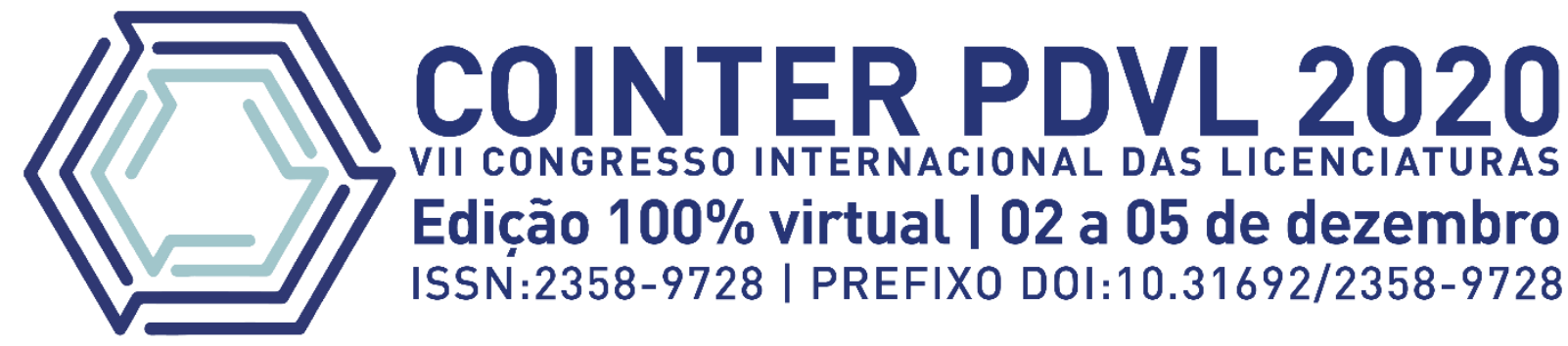

\title{
QUÍMICA AMBIENTAL NO ENSINO MÉDIO: UM OLHAR SOBRE A EDUCAÇÃO AMBIENTAL E OS PROBLEMAS AMBIENTAIS QUE AFETAM A CIDADE DE ITAJÁ/RN
}

\author{
ENVIRONMENTAL CHEMISTRY IN HIGH SCHOOL: A LOOK AT \\ ENVIRONMENTAL EDUCATION AND ENVIRONMENTAL PROBLEMS \\ AFFECTING THE CITY OF ITAJÁ/RN
}

\section{QUÍMICA AMBIENTAL EN LA ESCUELA SECUNDARIA: UNA MIRADA A LA EDUCACIÓN AMBIENTAL Y LOS PROBLEMAS AMBIENTALES QUE AFECTAN LA CIUDAD DE ITAJÁ/RN}

\author{
Apresentação: Comunicação Oral \\ Ana Raquel Lopes ${ }^{1}$; Monalisa Porto Araújo ${ }^{2}$; Leonardo Rafael Medeiros ${ }^{3}$
}

DOI: https://doi.org/10.31692/2358-9728.VIICOINTERPDVL.0332

\begin{abstract}
RESUMO
A temática apresentada neste estudo discute a possibilidade de ensinar a Química Ambiental no Ensino Médio, mediante temas referentes à Educação Ambiental. Este estudo tem como embasamento discussões referentes à Química Ambiental e Educação Ambiental dentro de uma abordagem conjunta. Essa abordagem foi centrada nos princípios da problematização, considerando o contexto local em que os estudantes do Ensino Médio da Escola Estadual João Manoel Pessoa estão inseridos. Assim, esse estudo objetivou responder à seguinte proposição: como a Química Ambiental pode contribuir para desenvolver ações de Educação Ambiental, levando em consideração os problemas ambientais que afetam a cidade de Itajá/RN? Além disso, o presente trabalho objetivou analisar como os conceitos estudados na disciplina de química podem ser articulados, utilizando a discussão dos problemas ambientais decorrentes das atividades das indústrias ceramistas, na perspectiva da Educação Ambiental. A pesquisa foi realizada em uma turma da $2^{\circ}$ série do Ensino Médio EJA da Escola Estadual João Manoel Pessoa - Itajá/RN, a partir da utilização de estratégias de pesquisa participante em uma sequência didática, envolvendo aplicação de questionários, realização de aulas, jogos e produção de material ilustrativo e avaliação. Os resultados obtidos demonstraram que o conhecimento dos alunos sobre a temática foi desenvolvido e consolidado a partir das atividades aplicadas no decorrer da intervenção, tendo em vista o aumento significativo da média de acertos dos questionários aplicados antes e depois das aulas e as interações vivenciadas no decorrer do processo de pesquisa. Portanto, verificamos que a relação entre a Química Ambiental e a Educação Ambiental contribui na formação de agentes conscientes capazes de identificar problemas e se mobilizarem na própria comunidade e que multiplicam atitudes ambientalmente corretas, bem como a reconstrução do saber científico pelos participantes.

Palavras-chaves: Ensino de Química, Problematização, Meio Ambiente, Percepção Ambiental.
\end{abstract}

\footnotetext{
${ }^{1}$ Licenciada em Química pelo IFRN, Campus Ipanguaçu. E-mail: raquel_lopes23@hotmail.com.

${ }^{2}$ Professora do Ensino Básico, Técnico e Tecnológico do IFRN, Campus Ipanguaçu. E-mail: monalisa.porto@ifrn.edu.br.

${ }^{3}$ Professor do Ensino Básico, Técnico e Tecnológico do IFRN, Campus Ipanguaçu. E-mail: leonardo.rafael@ifrn.edu.br.
} 


\section{QUÍMICA AMBIENTAL NO ENSINO MÉDIO}

\section{RESUMEN}

El tema presentado en este estudio discute la posibilidad de enseñar Química Ambiental en la Escuela Secundaria, a través de temas relacionados con la Educación Ambiental. Este estudio se basa en discusiones sobre Química Ambiental y Educación Ambiental dentro de un enfoque conjunto. Este enfoque se centró en los principios de problematización, considerando el contexto local en el que se insertan los estudiantes de ensino secundario de la Escuela Estatal João Manoel Pessoa. Así, este estudio tuvo como objetivo dar respuesta a la siguiente proposición: ¿cómo puede la Química Ambiental contribuir a desarrollar acciones de Educación Ambiental, tomando en cuenta los problemas ambientales que afectan a la ciudad de Itajá/RN? Además, el presente estudio tuvo como objetivo analizar cómo se pueden articular los conceptos estudiados en la disciplina química, utilizando la discusión de los problemas ambientales derivados de las actividades de las industrias cerámicas, em una perspectiva de la Educación Ambiental. La investigación se llevó a cabo en una clase de segundo grado en la Escuela Estatal João Manoel Pessoa - Itajá/RN, utilizando estrategias de investigación participativa em uma sequencia didática, envolviendo aplicación de cuestionarios, clases, juegos y producción de material ilustrativo y evaluación. Los resultados obtenidos demostraron que el conocimiento de los estudiantes sobre el tema se desarrolló y consolidó a partir de las actividades aplicadas durante la intervención, ante el aumento significativo en el promedio de respuestas correctas aplicadas antes y después de las clases y las interacciones vividas durante la intervención del proceso de investigación. Por tanto, verificamos que la relación entre Química Ambiental y Educación Ambiental contribuye a la formación de agentes conscientes capaces de identificar problemas y movilizarse en la comunidad y multiplicar actitudes ambientalmente correctas, así como la reconstrucción del conocimiento científico por parte de los participantes.

Palabras clave: Enseñanza de Química, Problematización, Medio Ambiente, Percepción Ambiental.

\section{ABSTRACT}

The theme presented in this study discusses the possibility of teaching Environmental Chemistry in High School, through themes related to Environmental Education. This study is based on discussions regarding Environmental Chemistry and Environmental Education within a joined approach. This approach was centered on the principles of problematization, considering the local context in which high school students at João Manoel Pessoa State School are inserted. Thus, this study aimed to answer the following proposition: how can Environmental Chemistry contribute to develop Environmental Education actions, taking into account the environmental problems that affect the city of Itajá/RN? In addition, this study aimed to analyze how the concepts studied in the chemistry discipline can be articulated, using the discussion of environmental problems arising from the activities of the ceramics industries, from the perspective of Environmental Education. The research was carried out in a 2nd grade class at João Manoel Pessoa State School - Itajá/RN, using participatory research strategies in a didactic sequence, involving application of questionnaires, classes, games and production of illustrative material and evaluation. The results obtained demonstrated that the knowledge of the students about the theme was developed and consolidated from the activities applied during the intervention, in view of the significant increase in the average number of correct answers applied before and after classes and the interactions experienced during the intervention of the research process. Therefore, we verified that the relationship between Environmental Chemistry and Environmental Education contributes to the formation of conscious agents capable of identifying problems and mobilizing themselves in the community and multiplying environmentally correct attitudes, as well as the reconstruction of scientific knowledge by the participants.

Keywords: Chemistry Teaching, Problematization, Environment, Environmental Perception.

\section{INTRODUÇÃO}

As questões ambientais vêm recebendo grande destaque no cenário internacional nas últimas décadas, em virtude de uma série de desequilíbrios decorrentes da forma como o ser humano vem se relacionando com a natureza. Dentre os principais destaques, temos os desastres 
ambientais, como o desflorestamento; destruição de hábitat; poluição e extinção de espécies. Esses são assuntos cada vez mais presentes no nosso cotidiano, exigindo uma nova postura e uma mudança na forma de agir dos cidadãos na convivência com o meio ambiente (MARTINE; ALVES, 2015).

Diante desse cenário, vê-se a necessidade de buscar possíveis caminhos para o enfrentamento da crise ambiental. Uma das alternativas que pode contribuir para se promover uma mudança efetiva de atitudes da sociedade encontra-se na reconstrução dos valores relativos à convivência do ser humano com a natureza por meio da educação. Mediante tal prerrogativa, a perspectiva da Educação Ambiental (EA) busca problematizar essa relação, com a finalidade de proporcionar o aumento da qualidade ambiental e bem-estar social (DIAS, 2010). Segundo Carvalho (2007), a EA é uma proposta educativa que nasce em um momento histórico complexo e faz parte de uma tentativa de responder aos sinais de falência do modo de vida atual, que não sustenta mais a promessa de felicidade, progresso e desenvolvimento, a partir de uma racionalidade científica.

Pode-se entender que a EA é um processo pelo qual o educando começa a obter conhecimentos acerca das questões ambientais, onde ele passa a ter uma nova visão sobre o meio ambiente, sendo um agente transformador em relação à conservação ambiental. Nesse sentido, a Química e a Química Ambiental (QA) são meios capazes de articular outros níveis de percepção e uma expansão na visão de problemas que afetam o ambiente. A construção da temática se deu a partir da observação da carência de ações relacionadas à EA no Ensino Médio e os problemas encontrados no município de Itajá/RN, bem como o interesse em explorar a Química mediante outros prismas. Levando em consideração o contexto local, a cidade apresenta alguns problemas que estão diretamente ligados ao meio ambiente. É uma cidade que possui um grande polo ceramista e, por essa razão, afeta diretamente o ar do município e a degradação dos solos, onde são retirados materiais para a fabricação de tijolos e telhas. Outra questão é a eutrofização, praticamente perene nas proximidades da Barragem Armando Ribeiro Gonçalves, também localizada no município (MOSCA, 2008).

Este trabalho parte da necessidade de construir com a escola oportunidades para a formação de cidadãos que compreendam a importância da preservação do meio ambiente. Foi desenvolvido com o objetivo de despertar a sensibilização dos alunos a partir da compreensão holística das relações existentes entre a atividade econômica ceramista, os consequentes impactos na cidade e o papel do ser humano na tentativa de prevenir os impactos negativos. As atividades desenvolvidas foram baseadas na questão: “Como a Química Ambiental pode contribuir para resolução de problemas ligados à Educação Ambiental, considerando o contexto 


\section{QUÍMICA AMBIENTAL NO ENSINO MÉDIO}

local de Itajá/RN, com a participação de alunos do Ensino Médio?’”.

\section{FUNDAMENTAÇÃO TEÓRICA}

\section{Educação Ambiental}

O mundo está vivendo uma era de grandes mudanças, tanto no âmbito social, econômico, tecnológico e ambiental. No geral, nem todas as mudanças beneficiam a sociedade positivamente. Os progressos trazem na bagagem, também, a degradação da vida humana e do meio ambiente, dos valores sociais e individuais. Viver diante de uma crise dos recursos naturais faz com que os conhecimentos sobre EA sejam essenciais na formação das pessoas, para torná-las mais conscientes e provocar mudança de comportamentos. Assim, é necessário estimular a participação dos indivíduos nas tomadas de decisões e adotar atitudes que possam minimizar os impactos ambientais na sociedade, assim podendo garantir um futuro com melhores condições para a sobrevivência da humanidade.

Diante dessa problemática, baseando-se nas inteligências múltiplas de Gardner (1994), o homem não nasce com a inteligência naturalista já desenvolvida, muito embora todos nós apresentamos a capacidade de desenvolvê-la a partir da interação com o meio. Nesse aspecto, a educação científica é fundamental, pois é possível conscientizar a população acerca das interrelações complexas existentes entre Ciência e Sociedade e possibilita a tomada de decisões na área ambiental com criticidade. Além disso, as preocupações coletivas referentes à EA revelam não somente o desrespeito do ser humano perante a natureza, mas também a falta de estrutura para tratar desta temática. Diante disso, discussões e ações em EA têm sido e devem ser cada vez mais difundidas (BOSA; TESSER, 2014).

A EA, segundo Cavalcante (2005), é um território comum a todos e deve estar inserida no Projeto Político Pedagógico das escolas, a partir de uma visão de mundo e sociedade que prevê a responsabilidade compartilhada para a preservação do meio ambiente. Nesse contexto, as questões ambientais requerem uma análise sistemática, levando em consideração o entendimento de que a realidade atual é um reflexo do processo historicamente construído na relação ambiente e sociedade, demandando, assim, uma mudança profunda na própria relação de como a humanidade se relaciona com o meio ambiente.

A preocupação de assegurar melhor qualidade de vida para nossa geração e para o futuro da humanidade está contemplada nas orientações curriculares para as escolas e é tratada pela Base Nacional Comum Curricular (BNCC). De acordo com a BNCC, a área de Ciências da Natureza e suas Tecnologias considera para o Ensino Médio, além da continuidade dos 
conteúdos iniciados no Ensino Fundamental, a manutenção de temas ligados à saúde e qualidade de vida.

\begin{abstract}
Em conformidade com a própria natureza da área no Ensino Médio, a BNCC propõe que os estudantes aprofundem e ampliem suas reflexões a respeito das tecnologias, tanto no que concerne aos seus meios de produção e seu papel na sociedade atual como também em relação às perspectivas futuras de desenvolvimento tecnológico. Desse modo, propõe continuidade ao tratamento dado no Ensino Fundamental, etapa na qual as tecnologias foram abordadas sob uma perspectiva de aplicação de conhecimentos e análise de seus efeitos sobre a saúde e a qualidade de vida das pessoas (BRASIL, 2018, p. 539).
\end{abstract}

Diante desse contexto, inserir a temática "Meio Ambiente" no currículo escolar vem promover reflexões acerca da necessidade de preservar e defender o meio ambiente, levando alunos e professores a se tornarem cidadãos comprometidos em desenvolver um caráter responsável com a manutenção da vida na Terra. Em busca do equilíbrio entre o homem e o ambiente, atribui-se a EA um caráter mais realista que busca a construção de um futuro desenvolvido a partir de uma lógica sustentável (VIEZZER; OVALLES, 1995). Dessa forma, podemos e devemos utilizar a EA como ferramenta para construir uma sociedade baseada na sustentabilidade, onde crescimento econômico, desenvolvimento social e preservação ambiental caminham juntos.

\title{
Química Ambiental e Ensino de Química
}

Diante das teorias empirista-positivistas da ciência, a execução de um ensino contextualizado e interdisciplinar torna-se difícil, pois a educação está cada vez mais ligada ao método científico, que por sua vez, apoia-se no ensino de conceitos (SANTOS; PRAIA, 1992). No entanto, a corrente Ciência-Tecnologia-Sociedade-Ambiente (CTSA), traz na atualidade, possibilidades de tratar aspectos emergentes, como as questões vinculadas aos problemas ambientais, dentro do Ensino de Ciências. É de fundamental importância a discussão de temas de caráter científico, social e econômico que possam contextualizar os conteúdos programáticos, presentes na matriz curricular do Ensino Médio, permitindo a conscientização de cidadãos quanto aos problemas do cotidiano (SANTOS; SCHNETZLER, 1996).

O Ensino de Química passado nas escolas dificulta que os alunos compreendam a Química e suas transformações de forma global. Dessa maneira, é preciso adotar uma abordagem que trabalhe os conteúdos de química numa perspectiva holística, focando na mudança de comportamento de cada um, e que auxilie na tomada de decisões dos estudantes, como indivíduos e cidadãos. Essa prática deve possibilitar ao aluno a compreensão tanto dos processos químicos em si quanto da construção de um conhecimento científico em estreita 


\section{QUÍMICA AMBIENTAL NO ENSINO MÉDIO}

relação com as aplicações tecnológicas e suas implicações ambientais, sociais, políticas e econômicas (MALDANER; ZANON, 2004).

Para que o ensino de química possa contribuir para o entendimento globalizante das temáticas ambientais, é necessário desafiar os estudantes com problemas reais, motivá-los e ajudá-los a superar as questões que parecem insuperáveis, permitindo a cooperação e o trabalho em grupo, assim como avaliá-los pelas atitudes em desenvolver ações que contribuam para a aprendizagem (GUIMARÃES, 2009).

No ano de 1994, surgiu a Divisão de Química Ambiental na Sociedade Brasileira de Química (SBQ) como resultado de uma intensa luta de pesquisadores que atuavam nessa área. Esses pesquisadores buscavam explicar e diagnosticar a qualidade e a quantidade de poluentes ambientais. Diante da necessidade de uma área voltada especificamente para a QA, profissionais que atuavam em outras áreas passaram a desenvolver pesquisar voltadas para o meio ambiente. Segundo a Diretoria de QA da SBQ (2011):

[...] a Química Ambiental estuda os processos químicos que ocorrem na natureza, sejam eles naturais ou ainda causados pelo homem, e que comprometem a saúde humana e a saúde do planeta como um todo. Assim, dentro dessa definição, a Química Ambiental não é a ciência da monitoração ambiental, mas sim da elucidação dos mecanismos que definem e controlam a concentração de espécies químicas candidatas a serem monitoradas. (DQASBQ, 2011)

Diante do cenário de desenvolvimento socioeconômico, surgiu a necessidade de aproximar as áreas da QA com a Educação Ambiental, na tentativa de haver um melhor entendimento em relação aos problemas ambientais provenientes do avanço econômico, mostrando a ciência como uma construção social permeada por interesses (CHASSOT, 2008).

Grande parte da vinculação entre QA e EA se dá por consequência dos processos químicos provocados por alguma interferência humana, seja pela degradação do solo, poluição do ar, poluição das águas, liberação de gases que contribuem para o efeito estufa, entre outros. Diante dos problemas encontrados, algumas respostas vêm sendo discutidas e um dos meios que cercam a busca por soluções é a QA, que traz conceitos que podem promover uma formação ecológica (ROCHA et al., 2004).

\section{Histórias em Quadrinhos na Educação}

As Histórias em Quadrinhos (HQ) são um tipo de gênero textual amplamente difundido no Brasil, caracterizado pela presença de recursos gráficos e textuais, representando um tipo de arte relacionada à contação de histórias. Diante do seu caráter lúdico e criativo, no final da década de 90, as HQs começaram a ser bastante difundidas no ambiente escolar, como resultado 
da necessidade de divulgação cultural nas escolas, bem como de inserção de outras linguagens e manifestações artísticas no ensino básico (VERGUEIRO; RAMOS, 2009).

Apesar de aparentemente simples, a leitura de HQs requer habilidades complexas da linguagem, uma vez que é preciso ir além dos elementos textuais, como diálogos e textos narrativos. Dessa maneira, o leitor precisa articular os elementos verbais com os não-verbais contidos nesse gênero textual, por exemplo, interpretando os tipos de balões, metáforas visuais, onomatopeias, dentre outros (GROENSTEEN, 2004).

A adaptação das HQ para o processo de aprendizagem vem sendo realizada em diversas áreas de ensino, como na literatura (VERGUEIRO; RAMOS, 2009), história (SANTOS; VERGUEIRO, 2012) e química (FRANCISCO JÚNIOR; GAMA, 2017). Isso acontece uma vez que a ludicidade presente nas HQs confere diversão e prazer à apropriação dos conhecimentos (CHATEAU, 1987), muitas vezes por envolver problemáticas e desafios em suas histórias. Assim, constata-se um grande potencial das HQs como ferramenta pedagógica.

$\mathrm{Na}$ área da química, a possibilidade de criar HQs com situações cotidianas do estudante pode aproximá-los à disciplina e conferir mais significado às práticas pedagógicas. Além disso, esse gênero textual apresenta uma boa aceitação pelos discentes, podendo ser utilizada, também, para auxiliar no desenvolvimento da leitura e nas suas capacidades metacognitivas (FRANCISCO JÚNIOR; GAMA, 2017). Dessa forma, as HQs são ferramentas promissoras, podendo ser utilizadas, em química, para se abordar uma gama de temáticas, sobretudo àquelas que concernem a vida dos estudantes.

\section{METODOLOGIA}

\section{Tipo da pesquisa}

Este estudo apresenta uma abordagem qualitativa, (GATTI, 2002) e seguiu a linha de pesquisa participante (BRANDÃO, 2001). Os procedimentos metodológicos envolveram a observação participante (BRANDÃO, 1984), aplicação de questionários e a vivência de uma sequência didática (ZABALA, 1998), promovendo a participação e construção coletiva da pesquisa.

Para sua execução, foram utilizadas atividades que estimularam os estudantes a observarem a realidade de modo crítico, possibilitando relacionar essa realidade com os conceitos estudados em sala de aula. Assim, analisou-se como a disciplina de química pode ser articulada utilizando a discussão dos problemas ambientais, decorrentes das atividades das indústrias ceramistas, na perspectiva da Educação Ambiental. 


\section{QUÍMICA AMBIENTAL NO ENSINO MÉDIO}

\section{Área de estudo}

A presente pesquisa foi realizada na Escola Estadual João Manoel Pessoa, durante o mês de novembro de 2019. A escola fica localizada no município de Itajá, mesorregião do Oeste Potiguar do estado do Rio Grande do Norte (IBGE, 1990). A cidade apresenta uma população de 7.515 habitantes, de acordo com o último censo demográfico, extensão territorial de 203.622 $\mathrm{km}^{2}$ e clima tropical semiárido (IBGE 2019). A maior economia do município está centralizada na produção de telhas, tijolos e lajotas, uma vez que a região é reconhecida como um importante polo ceramista do estado. A escolha da cidade de Itajá/RN para a realização deste trabalho se deu inicialmente pelo fato de ser um local que apresenta alguns problemas ambientais decorrentes do grande número de indústrias ceramistas na área urbana da cidade, tais como poluição do ar e a degradação do solo.

As modalidades de ensino ofertadas pela escola foco deste estudo são o Ensino Médio Regular e EJA, bem como o Ensino Técnico Subsequente, totalizando 332 alunos matriculados em 2019, em turmas nos turnos vespertino e noturno. A turma escolhida foi a da $2^{\mathrm{a}}$ série do Ensino Médio EJA do turno noturno, a qual possuía um total de 15 alunos. A escolha da turma se deu tendo em vista a grande carência de ações de EA para o público da modalidade EJA.

\section{Etapas metodológicas}

A pesquisa foi realizada em três fases. A primeira fase compreendeu a utilização de dois questionários, os quais foram aplicados antes das intervenções do projeto. O primeiro questionário tinha a finalidade de compreender o nível de conhecimento prévio dos alunos sobre a EA e como eles conseguiam identificar esse tema presente em suas vidas. Em outro momento, foi aplicado o segundo questionário, com o intuito de avaliar o conhecimento prévio dos alunos sobre a temática da QA, relacionando com sua percepção ambiental a respeito das atividades ceramistas na região.

A segunda fase da pesquisa compreendeu dois encontros, de 45 minutos cada, com a turma, em que foi aplicada a sequência didática, que compreendeu aulas expositivas dialógicas baseadas na realidade das cerâmicas presentes no município. Os conhecimentos prévios dos alunos analisados a partir dos questionários foram utilizados como ponto de partida para as discussões das intervenções.

$\mathrm{Na}$ terceira fase da pesquisa, foi realizada a avaliação da sequência didática baseada no aprendizado dos alunos referente aos conteúdos de EA e QA. Nesse momento, foi realizado um jogo de perguntas e respostas sobre os assuntos e os alunos foram engajados na produção de HQs, segundo a metodologia HQ detalhada nos estudos de (PEREIRA, SANTOS, 2009). A 
turma foi organizada em 5 grupos para desenvolver HQs sobre os assuntos vistos em sala de aula (Meio Ambiente, Educação Ambiental e Química Ambiental). Cada grupo ficou livre para produzir histórias de temas diversos, desde que integrassem temáticas dentro desses três assuntos. Posteriormente, as HQs produzidas foram socializadas por todos da turma, para finalizar a aplicação da sequência didática.

\section{RESULTADOS E DISCUSSÃO}

\section{Análise do nível de conhecimento sobre Educação Ambiental}

A partir das respostas dos questionários, 13 alunos (87\%) responderam que tinham interesse em conhecer sobre o tema e apenas 2 alunos (13\%) responderam que não tinham interesse. Ao serem questionados sobre existir na escola alguma atividade ou projeto sobre EA, todos responderam que não. Entre as disciplinas que abordam sobre o tema meio ambiente, 11 alunos (73\%) responderam que a única que aborda é a biologia, apenas 1 aluno (7\%) respondeu que as disciplinas de química e biologia possuem abordagens sobre meio ambiente, e 3 alunos (20\%) disseram que nenhuma disciplina traz conteúdos relacionados ao tema para a sala de aula (dados não apresentados).

Segundo a Política Nacional de Educação Ambiental, em seu Art. 4º, inciso III, a EA tem como princípio "o pluralismo de ideias e concepções pedagógicas, na perspectiva da inter, multi e transdisciplinaridade" (BRASIL, 1999). Assim, percebe-se que, apesar de a abordagem interdisciplinar das temáticas ambientais ser fomentada por lei, ainda existe resistência por diversos professores em adotarem a EA em sua prática pedagógica. Para compreender toda a complexidade inerente ao conceito de meio ambiente, é imprescindível que haja um trabalho em conjunto de professores de diversas áreas, para romper com a prática ultrapassada de compartimentalização dos conhecimentos, bem como favorecer a criticidade e a motivação para resolver problemas contemporâneos (BRASIL, 2000; CONRADO; SILVA, 2017).

Sobre a fonte de informação sobre meio ambiente, 9 alunos (60\%) afirmaram aprender na escola, 5 alunos (33\%) através da internet e 1 aluno (7\%) com o auxílio de livros. Quando indagados se abordar sobre a EA nas aulas de química facilitaria ou não a aprendizagem, 12 alunos (80\%) responderam de maneira afirmativa e 3 alunos (20\%) responderam que não. A última pergunta do questionário era discursiva e questionou-se se o que eles entendem sobre meio ambiente. Analisando as respostas, foi selecionada a seguinte fala de um aluno:

Aluno 1: "Que devemos preservar sempre o meio ambiente. É importante mantê-lo limpo." 


\section{QUÍMICA AMBIENTAL NO ENSINO MÉDIO}

A maioria dos alunos apresentou respostas como essa e pode-se analisar que o conhecimento deles sobre o meio ambiente restringem-se muito à natureza, visão conhecida como concepção naturalista (REIGOTA, 2012). Esse resultado é uma evidência do fato de a EA ser pouco vista na escola e em atividades cotidianas dos discentes. Por essa razão, a importância de se discutir as questões ambientais e formar cidadãos críticos e conscientes, que estejam aptos a decidir e atuar na realidade socioambiental, é indiscutível. A escola deve proporcionar um ambiente coerente e fornecer informações coesas e concretas para o sucesso dos projetos relacionados à área. Mas apesar de haver essa necessidade, surgem vozes, como o caso de Tristão (2008), que nos fala da dificuldade de se efetivar a EA no contexto interdisciplinar:

(...) a abordagem interdisciplinar da educação ambiental dificilmente se efetiva nas ações pedagógicas do espaço escolar, haja vista que, para sua realização, além de suscitar uma descentralização do poder, a escola tem que ter autonomia, o que é extremamente complicado, porque essas unidades estão sempre submetidas às políticas públicas das esferas a que pertencem apesar da existência de inúmeros projetos e tentativas de ações pedagógicas interdisciplinares (TRISTÃO, 2008, p. $110)$.

Portanto, reiteramos que é fundamental que os docentes, independente da disciplina que ministram, trabalhem com seus alunos e tragam temas sobre o meio ambiente e temáticas atuais. Além disso, é necessário desenvolver o raciocínio dos educandos e apresentar propostas que tragam resultados concretos, para que eles façam ligação com o que é ensinado e com o que eles vivem, pois a mudança de cenário, em se tratando de questões ambientais, exige constante atualização.

\section{Análise da percepção dos alunos sobre Química Ambiental}

Quando os alunos foram indagados sobre o conceito de Química Ambiental, 12 alunos (80\%) conseguiram responder corretamente, afirmando que compreendem o ramo da química que estuda as transformações ambientais, sejam eles naturais ou causados pelo homem (Figura 1). Dessa forma, verifica-se que a maioria dos alunos tinham alguma noção do que representa essa área do conhecimento.

Quando questionados sobre que ambientes (água, solo e/ou ar) são poluídos por resíduos liberados por indústrias, 9 (60\%), 11 (73\%) e 13 (87\%) afirmaram que as atividades industriais contribuem para a poluição aquática, dos solos e atmosférica, respectivamente (Figura 2). Assim, constata-se que a poluição atmosférica foi mais facilmente identificada pelos estudantes como uma das consequências negativas de indústrias no ambiente. Mesmo assim, a maioria dos alunos tinham uma compreensão de que as atividades industriais apresentam múltiplos 
impactos nocivos.

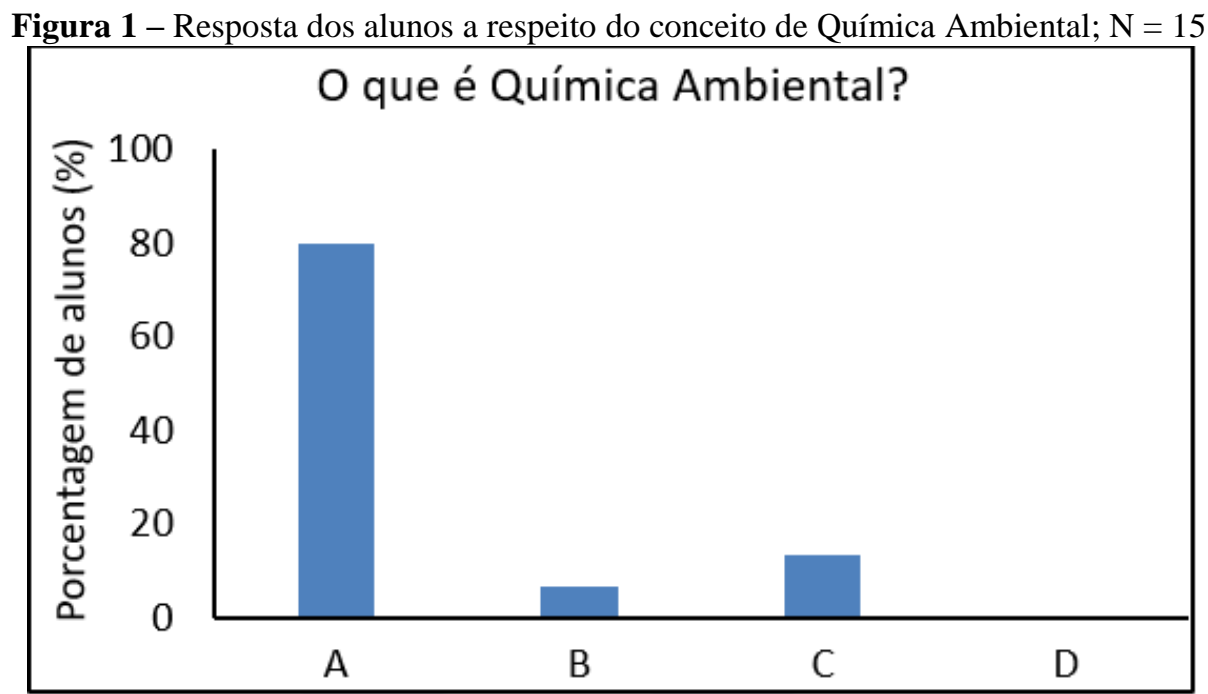

Legenda: A. É o ramo da química que estuda as transformações ambientais sejam eles naturais ou causados pelo homem; B. É a química da natureza; C. É o estudo da química presente no meio ambiente; D. É a química das indústrias que são prejudiciais ao meio ambiente.

Fonte: Própria (2020).

Figura 2 - Conhecimento dos alunos a respeito da ação poluidora dos resíduos de origem industrial; N = 15.

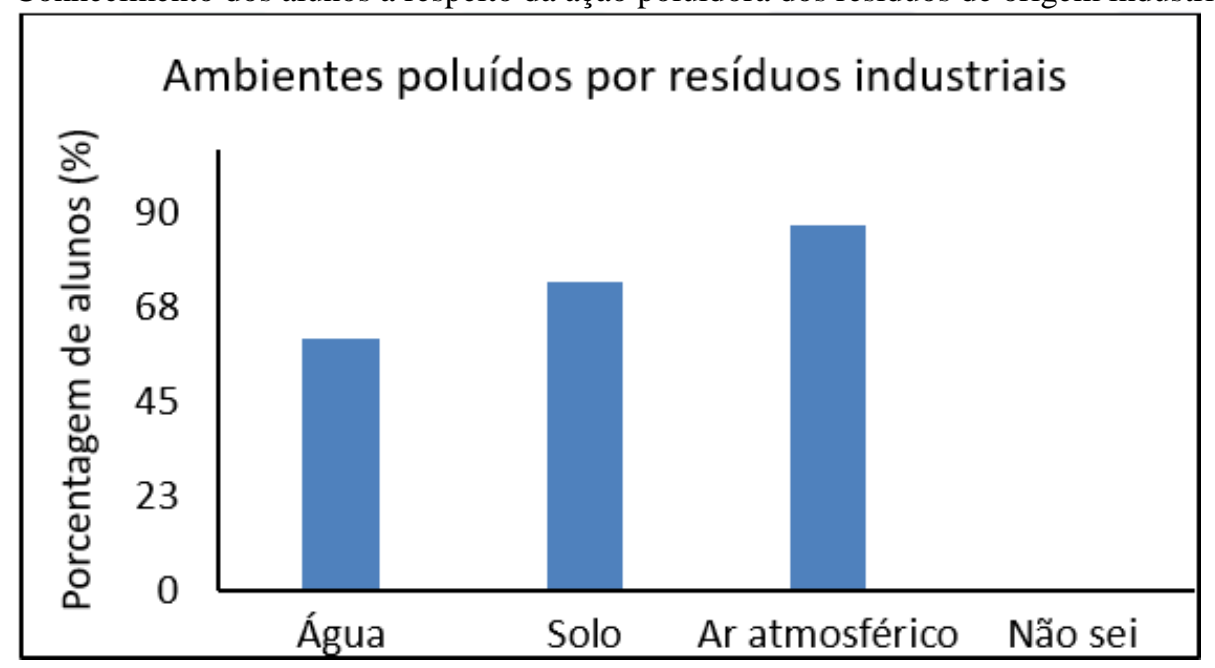

Fonte: Própria (2020).

No tocante à poluição atmosférica, os alunos foram apresentados a quatro situações envolvendo efeito estufa, chuva ácida e buraco na camada de ozônio e deveriam julgar as sentenças como verdadeiras ou falsas. Após analisar as respostas, verificou-se que 4 (27\%), 3 (20\%), $6(40 \%)$ e $2(13 \%)$ alunos conseguiram acertar 1, 2, 3 e 4 sentenças, respectivamente (Figura 3). Assim, constatamos que cerca de metade dos alunos apresentaram um bom conhecimento a respeito do assunto, muito embora apenas 2 conseguiram distinguir corretamente todos esses fenômenos. A confusão em relação a esses fenômenos envolvendo a química atmosférica é bastante comum (BEZERRA; GONÇALVES, 2007), o que demonstra a importância de se realizar intervenções de EA para conseguir elucidar a diferença entre esses 


\section{QUÍMICA AMBIENTAL NO ENSINO MÉDIO}

fenômenos, para que, assim, seja possível conhecer as medidas de prevenção e mitigação dos efeitos negativos dessas ações antrópicas.

Figura 3 - Conhecimento sobre os diferentes fenômenos envolvendo a química atmosférica (efeito estufa, chuva ácida e buraco da camada de ozônio) em uma questão com quatro itens de verdadeiro ou falso; $\mathrm{N}=15$.

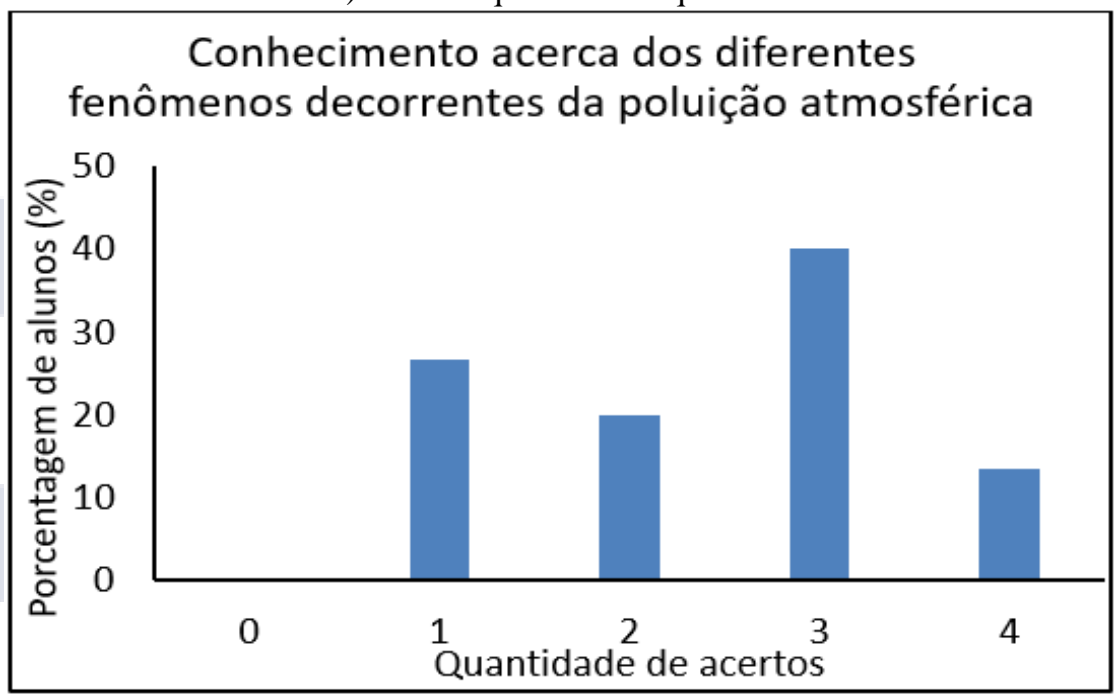

Fonte: Própria (2020).

Quando apresentados a quatro medidas que apresentam desdobramentos na poluição atmosférica, das quais três tinham efeito positivo e uma tinha efeito negativo, apenas 5 estudantes (33\%) conseguiram identificar corretamente a ação negativa como sendo diminuir a criação de áreas verdes nas cidades (Figura 4). Esse resultado reforça ainda mais a necessidade de intervenção com os alunos, uma vez que o conhecimento acerca das medidas de amenização da poluição atmosférica é de suma importância para a melhoria da qualidade ambiental.

Figura 4 - Conhecimento dos alunos acerca de formas de se amenizar a poluição atmosférica; $\mathrm{N}=15$.

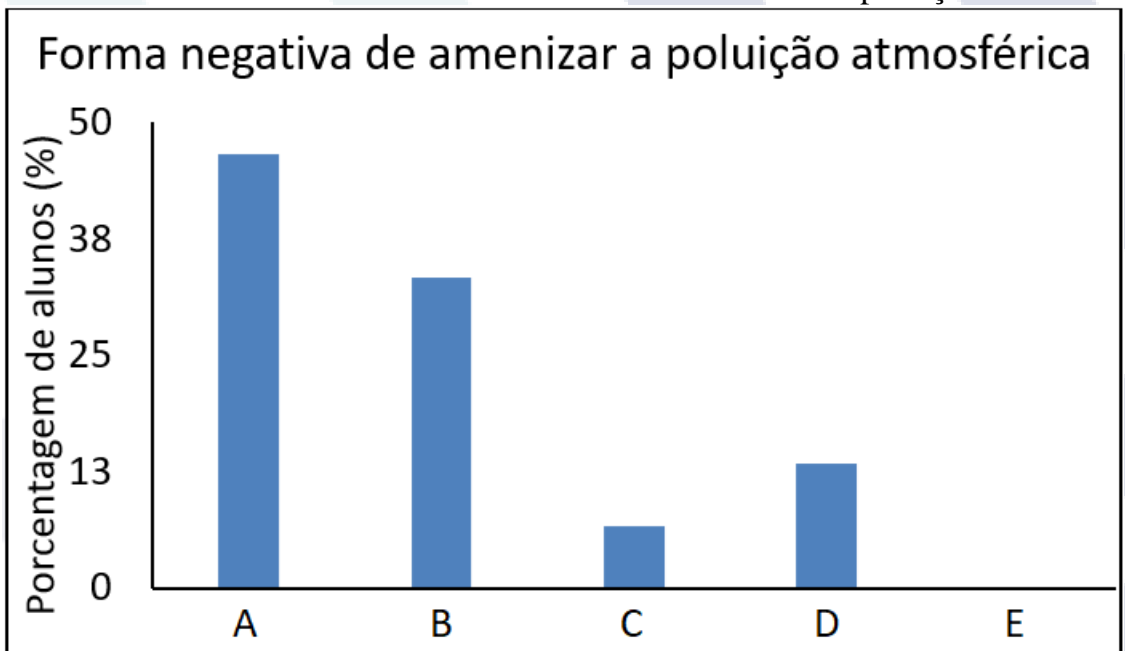

Legenda: A. Maior rigor nas leis que regem as instalações de fábricas e indústrias; B. Diminuir a criação de áreas verdes nas cidades; C. Melhorar o sistema de transporte coletivo para a diminuição de carros nas ruas; D. Incentivar a criação de tecnologias menos poluentes.

Fonte: Própria (2020). 
As duas últimas questões eram voltadas para os problemas locais da cidade, vivenciados pelos próprios alunos, e eram muito semelhantes. Quando indagados se eles achavam que a produção de cerâmica na cidade contribuía para a poluição do município, a maioria, representada por 11 alunos (73\%), respondeu de forma afirmativa (Figura 5A). Entretanto, ao perguntarmos se a retirada do barro, utilizado para produzir cerâmica, prejudicava o meio ambiente, apenas 7 estudantes (47\%) afirmaram que sim (Figura 5B). Esses resultados evidenciam que alguns alunos não conseguiam associar a exploração da argila como uma atividade que impacta negativamente o ambiente. Essa pergunta reforça o resultado apresentado na Figura 2, em que os alunos associaram a atividade ceramista mais com a poluição atmosférica do que com a poluição e degradação do solo e da água. Dessa forma, percebe-se a necessidade de intervenção para a ampliação da compreensão desses estudantes a respeito das complexidades que concernem às questões ambientais, tendo em vista que somente com essa compreensão mais global é possível desenvolver o pensamento crítico e a resoluções dos problemas (CONRADO; SILVA, 2017).

Figura 5 - Percepção dos alunos sobre: A) ação poluidora das indústrias ceramistas; e B) retirada do barro para produção de cerâmica; $\mathrm{N}=15$.

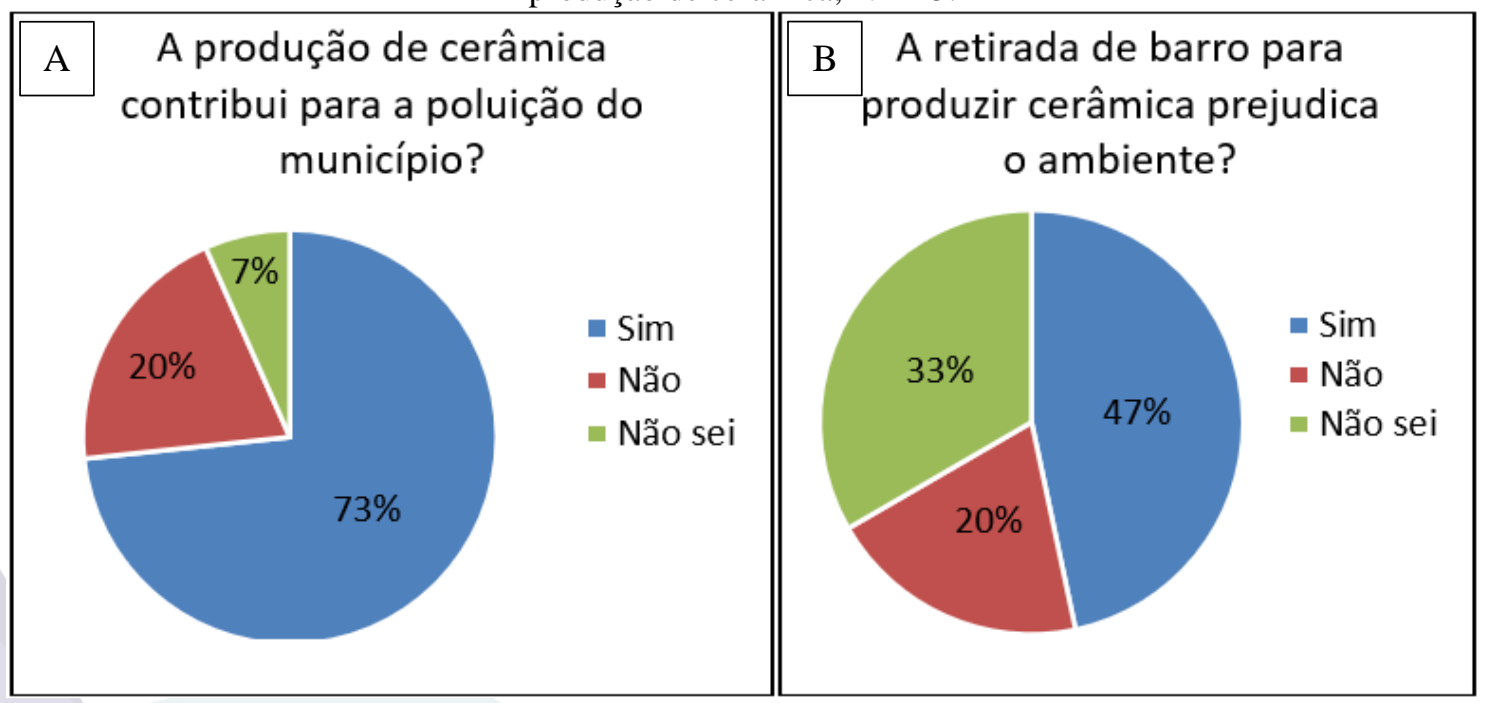

Fonte: Própria (2020).

Quando questionados sobre que medidas eram necessárias e importantes para minimizar o impacto das cerâmicas na cidade, a princípio, 10 alunos (67\%) responderam que não sabiam e 5 alunos (33\%) responderam que uma medida importante seria a diminuição da fumaça proveniente das chaminés, porém nenhum estudante apresentou uma medida concreta que viesse a proporcionar uma mudança nos impactos. Além disso, o fato de terem citado apenas a fumaça das chaminés reforça, mais uma vez, a visão limitada dos alunos acerca dos múltiplos impactos das indústrias no município. Assim, este trabalho reforça a necessidade de 


\section{QUÍMICA AMBIENTAL NO ENSINO MÉDIO}

desenvolver ações e fomentar discussões de EA nas escolas, a fim de ampliar a compreensão holística das questões ambientais com estudantes do ensino básico (BOSA; TESSER, 2014).

\section{Aplicação da sequência didática}

Como os alunos já tinham certo entendimento de que as indústrias ceramistas presentes no município contribuíam para a poluição da cidade antes da intervenção, foi possível utilizar esse fato para auxiliar a despertar a preocupação neles para a importância de se discutir as questões ambientais enquanto cidadãos, para que houvesse o desenvolvimento do sujeito ecológico. Além disso, como eles apresentavam algumas dificuldades em identificar os impactos das indústrias ceramistas na água e no solo, bem como citar medidas que pudessem minimizar esses impactos, esses assuntos foram reforçados durante a aplicação da sequência didática.

Após as intervenções, quando indagados para explicar se a retirada do barro trazia impactos negativos ao ambiente, alguns alunos responderam:

Aluno 2: "Porque o solo fica danificado e acabam com as áreas verdes."

Aluno 3: "Porque causa erosão no solo e forma crateras enormes."

Além disso, ao perguntarmos novamente sobre que medidas poderiam ser adotadas por essas indústrias para minimizar os impactos negativos no meio ambiente, obtivemos respostas mais objetivas, como traz a fala do aluno a seguir:

Aluno 4: “A utilização de filtros nas chaminés e o uso de serragem no lugar da lenha."

Observa-se, portanto, que os alunos conseguiram compreender bem o que foi dado nas aulas durante as intervenções. Eles conseguiram entender o quão prejudicial é a ação humana sobre a natureza e o meio ambiente, bem como compreenderam algumas medidas de prevenção dos impactos. Assim, os alunos conseguiram entender a necessidade de mudanças no funcionamento das indústrias e que essas medidas são capazes de proporcionar melhorias ao meio ambiente e as gerações futuras.

Os resultados observados neste estudo reafirmam a importância de se contextualizar os conteúdos das disciplinas do Ensino Médio à realidade do aluno, sendo possível uma conscientização mais efetiva dos estudantes para os problemas vivenciados em seu cotidiano (SANTOS; SCHNETZLER, 1996). Além disso, essas discussões de caráter científico, 
envolvendo as esferas social e econômica, evidenciam o potencial da QA na busca de soluções de problemas da realidade, contribuindo para a formação ambiental e humana dos estudantes (ROCHA et al., 2004).

\section{Produção das HQs}

Ao final das intervenções, cinco HQs foram produzidas pela turma, duas das quais estão apresentadas na Figura 6.

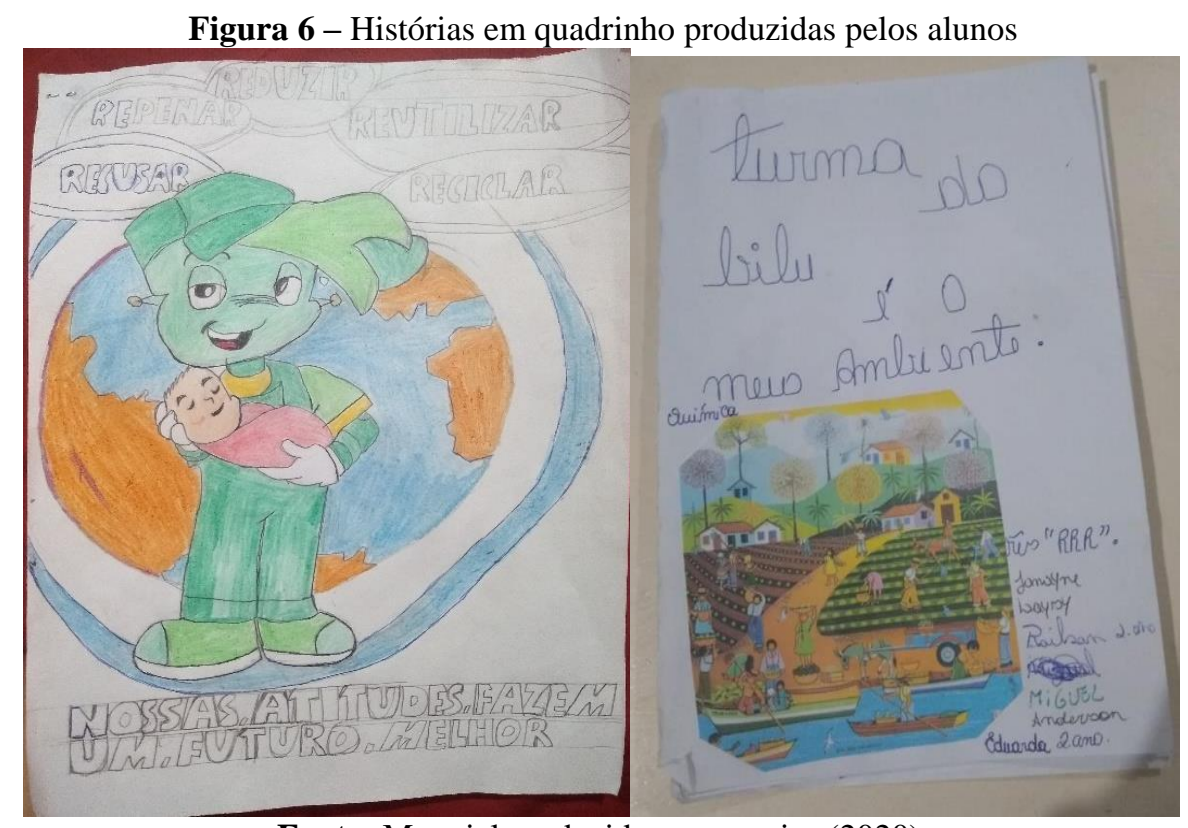

Fonte: Material produzido na pesquisa (2020).

Durante a exposição das HQs na turma, foi observado que vários alunos levantaram questionamentos e críticas construtivas a respeito dos materiais elaborados. Eles puderam enxergar vários pontos relacionados às histórias, como as imagens presentes e a escrita dos colegas. Foi observada também, pelos alunos, a coerência das histórias, se elas tratavam sobre o tema de maneira adequada e se a história trazia bastante informação para o leitor.

Constatamos que a produção das HQs foi bastante exitosa, tendo em vista que os estudantes conseguiram contextualizar as histórias para a realidade de Itajá, demonstrando uma capacidade crítico-reflexiva e criativa. Essa vivência com os alunos demonstra o grande potencial que as HQs apresentam para o desenvolvimento das funções metacognitivas, se apresentando como uma ferramenta lúdica e convidativa à aprendizagem (FRANCISCO JÚNIOR; GAMA, 2017).

Uma das formas de se alcançar um ensino de ciências pautado no letramento científico passa pela criação e avaliação de materiais didáticos que promovam o interesse dos alunos pela 


\section{QUÍMICA AMBIENTAL NO ENSINO MÉDIO}

ciência e o entendimento de como os conceitos científicos aprendidos na escola interferem no modo como estes veem e se relacionam com os fenômenos naturais. Assim, verificamos que as HQs contribuíram para a aquisição do conhecimento, problematizando a realidade dos estudantes e, conforme Santos e Vergueiro (2012) apontam, ampliando suas capacidades linguísticas e atendendo às necessidades do seu processo de ensino-aprendizagem.

\section{CONCLUSÕES}

A partir dos conhecimentos da área da QA, este trabalho promoveu a aplicação de uma sequência didática na disciplina de química a partir da problematização de uma situação real envolvendo o impacto antrópico das indústrias ceramistas presentes na cidade de Itajá/RN, como uma ação de EA. A EA contribui para a inclusão do indivíduo a partir do momento em que aborda as relações do homem com a sociedade e a natureza e leva o educando a refletir e agir, suscitando nele uma visão crítica da realidade ambiental. Ao implementar as atividades de EA, observou-se a procura pelo conhecimento de forma cooperativa e participativa, resultando no posicionamento mais claro e consciente dos alunos frente aos problemas ambientais locais, comprovados pela participação e atividades executadas.

Com a realização das atividades e a abordagem dos problemas ambientais locais da indústria ceramista nas aulas de química do Ensino Médio, os alunos encontraram nessas aulas a oportunidade para o desenvolvimento da consciência ambiental, necessário para a construção do sujeito ecológico. O tema abordado possibilitou o diálogo e a aproximação entre professor e alunos, o que tornou o estudo e a convivência muito mais prazerosos, havendo mais vontade em conhecer sobre o tema proposto.

Portanto, com os resultados obtidos, foi possível constatar que a intervenção e a proposta pedagógica e metodológica empregada foi viável, possibilitando a compreensão da temática ambiental pelos alunos e contribuindo de forma relevante para a reflexão e discussão desses assuntos. Mais estudos e ações de EA, como a realizada neste trabalho, são necessários para abordar, sob múltiplos olhares, toda a complexidade que permeia o meio ambiente. Assim, é possível contribuir para uma formação humana e social cada vez mais sustentável dos nossos alunos.

\section{REFERÊNCIAS}

BEZERRA, T. M. O.; GONÇALVES, A. A. C. Concepções de meio ambiente e educação ambiental por professores da Escola Agrotécnica Federal de Vitória de Santo Antão-PE. Biotemas, v. 20, n. 3, 2007. 
BOSA, C. R.; TESSER, H. C. B. Desafios da educação ambiental nas escolas municipais do município de Caçador-SC. Revista Monografias Ambientais - REMOA, v. 14, n. 2, 2014.

BRANDÃO, C. R. (Org.). Pesquisa participante. São Paulo: Brasiliense, 2001.

BRANDÃO, C. R. Participar-pesquisar. In: BRANDÃO, C. R. (Org.). Repensando a pesquisa participante. São Paulo: Brasiliense, 1984.

BRASIL. Lei No 9.795 de 27 de abril de 1999. Política Nacional de Educação Ambiental. Disponível em: <http://www.planalto.gov.br/ccivil_03/LEIS/L9795.htm>. Acesso em: 13 mai. 2020.

BRASIL. Parâmetros Curriculares Nacionais: Ensino Médio. MEC, Secretaria de Educação Média e Tecnológica. Brasília, DF, 2000. Disponível em: <http:// portal.mec.gov.br/seb/arquivos/pdf/blegais.pdf>. Acesso em: 07 mai. 2020.

BRASIL. Secretaria de Educação Básica. Base Nacional Comum Curricular: Ensino Médio. Brasília: MEC, 2018.

CAVALCANTE. L. O. H. Currículo e Educação Ambiental: trilhando os caminhos percorridos, entendendo as trilhas a percorrer. In: JÚNIOR, L. A. F. (Org.). Encontros e caminhos: formação de educadoras(es) ambientais e coletivos educadores. Brasília: MMA, Diretoria de Educação Ambiental, 2005.

CHASSOT, A. Sete escritos sobre educação e ciência. São Paulo: Cortez, 2008.

CARVALHO, V. S. Educação ambiental e os PCNs. In: Módulo IV - Educação Ambiental. Cursos de Pós-Graduação Lato Senso / Instituto A Vez do Mestre. Rio de Janeiro, 2007.

CHATEAU, J. O jogo e a criança. São Paulo: Summus, 1987.

CONRADO, L. M. N.; SILVA, V. H. Educação ambiental e interdisciplinaridade: um diálogo conceitual. R. Gest. Sust. Ambient., v. 6, n. 3, 2017.

DIAS, G. F. Educação Ambiental: princípios e práticas. 9ª ed. São Paulo-SP: Gaia, 2010.

DQASBQ. Divisão da Química Ambiental da Sociedade Brasileira de Química. 2011. Disponível em: http://www.quimica.ufpr.br/sbgamb/. Acesso em: 14 de mai. 2020.

FRANCISCO JÚNIOR, W. E.; GAMA, E. J. S. História em quadrinhos para o ensino de química: contribuições a partir da leitura de licenciandos. Revista Electrónica de Enseñanza de las Ciencias, v. 16, n. 1, 2017.

GARDNER, H. Estruturas da mente. A Teoria das Inteligências Múltiplas. Porto Alegre: Artes Médicas, 1994.

GATTI, B. A. A construção da pesquisa em educação no Brasil. Brasília: Plano, 2002.

GROENSTEEN, T. História em quadrinhos: essa desconhecida arte popular. João Pessoa: Marca de Fantasia, 2004. 
GUIMARÃES, C. C. Experimentação no Ensino de Química: Caminhos e Descaminhos Rumo à Aprendizagem Significativa. São Paulo, 2009.

IBGE. Instituto Brasileiro de Geografia e Estatística. Divisão regional do Brasil em mesorregiões e microrregiões geográficas. Biblioteca IBGE. 1: 44-47. 1990. Disponível em: <https://biblioteca.ibge.gov.br/visualizacao/livros/ liv2269_1.pdf>. Acesso em: 14 mai. 2020.

IBGE. Instituto Brasileiro de Geografia e Estatística. Cidades e Estados, 2019. Disponível em: <https://www.ibge.gov.br/cidades-e-estados/rn/itaja.html>. Acesso em: 14 mai. 2020.

MALDANER, O. A.; ZANON, L. B. Situação de Estudo: uma organização do ensino que extrapola a formação disciplinar em Ciências. In: MORAES, R.; MANCUSO, R. Educação em Ciências: Produção de Currículos e Formação de Professores. Ijuí: Ed. Unijuí, 2004.

MARTINE, G.; ALVES, J. E. D. Economia, sociedade e meio ambiente no século 21: Tripé ou trilema da sustentabilidade? R. Bras. Est. Pop., v. 32, n. 3, 2015.

MOSCA, V. P. Eutrofização do reservatório Engenheiro Armando Ribeiro Gonçalves, no Rio Grande do Norte: Implicações para o abastecimento público e para a piscicultura intensiva em tanques-rede. Natal, 2008. 73 p. Dissertação (Mestrado em Bioecologia Aquática). Universidade Federal do Rio Grande do Norte, 2008.

PEREIRA, E. G. C.; SANTOS, T. C. O uso de oficinas de histórias em quadrinhos como instrumento de avaliação no ensino de Ciências. In: I Simpósio em Ensino de Ciências e Meio Ambiente do Rio de Janeiro, 2009, Volta Redonda, RJ. Anais. Volta Redonda-RJ: UNIFOA, p. 75, 2009.

REIGOTA, M. O que é educação ambiental. $2^{\text {a }}$ ed. São Paulo-SP: Brasiliense, 2012.

ROCHA, J. C.; CARDOSO, A. A.; ROSA, A. H. Introdução a Química Ambiental. [S. l.]: Bookman, 2004.

SANTOS, M. E.; PRAIA, J. F. Percurso de mudança na Didáctica das Ciências: Sua fundamentação epistemológica. In: CACHAPUZ F. (Org.), Ensino das Ciências e Formação de Professores: Projecto MUTARE 1. Aveiro: Universidade de Aveiro, 1992.

SANTOS, R. E.; VERGUEIRO, W. Histórias em quadrinhos no processo de aprendizado: da teoria à prática. EccoS - Rev. Cient., São Paulo, n. 27, 2012.

SANTOS, W.; SCHNETZLER, R. Função Social: O que significa ensino de Química para formar o cidadão? Química Nova na Escola, n. 4, 1996.

TRISTÃO, M. A educação ambiental na formação de professores. 2. Ed. São Paulo: Annablume; Vitória: Fapitec, 2008.

VERGUEIRO, W.; RAMOS, P. (Org.). Quadrinhos na educação: da rejeição à prática. São Paulo: Contexto, 2009.

VIEZZER M.; OVALLES, O. Manual latino americano de educação ambiental. São Paulo: 
LOPES et al.

Gaia, 1995.

ZABALA, A. A Prática educativa: como ensinar. Porto Alegre: ArtMed, 1998. 